\title{
Using Rapid City Surveys to Inform Municipal Social Policy - An Application in Cali, Colombia
}

\author{
Jesko Hentschel \\ World Bank \\ 1818 H-Street, Washington D.C. \\ Jhentschel@worldbank.org
}

\begin{abstract}
:
Many developing countries assign local governments increasing responsibilities in fighting poverty. This requires local social policy to go beyond the execution of centrally designed and funded education and health programs. Hence, local governments and their partners have both an opportunity and a need to analyze key local bottlenecks for poverty reduction and social development. Drawing on an example from Cali, Colombia, this paper describes a tool for such policy formulation at the local level, a rapid city household survey. Although the survey uses pre-coded and closed-ended questions, it is contextual in the sense that it is tailor-made to social and economic conditions in Cali. The survey places particular emphasis on collecting key quantitative information, such as household welfare and service access, as well as qualitative information, such as service evaluations and population priorities. Combining the quantitative and qualitative data allows, for example, the mapping of population budget priorities or service satisfaction levels by welfare group. Rapid city household surveys could provide an important tool for the development of local social policies.
\end{abstract}

Keywords: Latin America, Colombia, urban poverty, city development strategy, service satisfaction, contextual surveys

\section{World Bank Policy Research Working Paper 3369, August 2004}

The Policy Research Working Paper Series disseminates the findings of work in progress to encourage the exchange of ideas about development issues. An objective of the series is to get the findings out quickly, even if the presentations are less than fully polished. The papers carry the names of the authors and should be cited accordingly. The findings, interpretations, and conclusions expressed in this paper are entirely those of the authors. They do not necessarily represent the view of the World Bank, its Executive Directors, or the countries they represent. Policy Research Working Papers are available online at http://econ.worldbank.org.

\footnotetext{
This paper is based on an analysis of poverty in Cali carried out as part of the City Development Strategy for Cali which the Municipality of Cali and the World Bank conducted from April 1999 to April 2000 (World Bank 2002). Financial support from the Bank/Netherlands Partnership Program, which financed the household survey and several background reports, is gratefully acknowledged. Kalpana Mehra and Radha Seshagiri contributed excellent technical research to the paper. Fernando Urrea from the Universidad Del Valle and Norbert Schady from the World Bank developed a large part of the questionnaire. The survey was fielded and the results tabulated by the Centro Nacional de Consultoria. Alexandra Ortiz, the team leader for the City Development Strategy, provided advice and comments during the whole project. Many thanks for comments and information are due to Jairo Arboleda, Tim Campbell, Elio Codato, Nigel Harris, Danny Leipziger, Gerald Martin, Carlos Ortiz, Fernando Rojas, Pilar Solans, Fernado Urrea and Fabio Velasquez.
} 


\section{Introduction}

On a global scale, developing countries have become more decentralized since the 1970s. As reported in the World Development Report 1997, in many countries the postcolonial period of nation-building during the 1950s and 1960s was followed by a shifting of public responsibilities toward lower levels of government. Decentralization can take many forms, ranging from administrative decentralization, in which specific state functions are transferred to lower levels of government while retaining budget authority at the central level, to the complete devolution of resources and political authority to local governments. One of the driving forces for such processes is the possibility of matching core public services with local preferences. Consequently, decentralization processes often start with passing the responsibility of planning and executing services in education, health, water, sanitation, garbage collection etc. to lower levels of government. Later in the process, local governments are also provided increased possibilities to influence and structure the local economy. With such processes, important instruments of social policy to reduce poverty become the responsibility of local governments.

With the need to design local anti-poverty strategies comes the need for local information. Such local information has at least two dimensions. One is to obtain quantitative data on poverty, its distribution and relationship to factors such as service access, the labor market, education or health. The second is to obtain feedback from the population, and especially the poor, on their satisfaction with current public (and private) programs as well as to assess priorities for future local policies, including for public spending.

This paper reports on the implementation and use of a rapid, integrative city survey in Cali, Colombia, to meet such local information needs. The rapid survey was an input into the design of a comprehensive development strategy for the city, which was undertaken by the Municipality of Cali with support from the World Bank. Requirements of the survey were that it had to be designed and implemented rather quickly to feed into the process of strategy formulation and that it had to be relatively moderate in cost so that the municipality would be able to field it as a monitoring survey out of its own budget in the future. Given these restrictions, it was to be as comprehensive as possible, catering to the need for quantitative information on poverty as well as for more qualitative information on perceptions and priorities.

Survey results proved insightful for local policy formulation in four areas. First, the survey collected information on a variety of poverty characteristics that produced, in part, 
surprising results as to the existence of hunger in the city and the pattern of unemployment. Second, using the quantitative data, the survey allowed us to match the geographical distribution of expenditures in the city with the distribution of poverty at the sub-municipal (comuna) level. A strong anti-poor bias for all expenditure categories emerged. Third, combining the qualitative and quantitative information, we found that service satisfaction levels of the population varied significantly across services but very little by income group. This was important as it allowed for the development of broad, integrative social policies. Fourth, budget priorities of the population showed clear winners and losers, with education and health at the top and sport arenas and police at the bottom of the list of services deserving more funding. The large and costly metro project - a cornerstone of Cali's development plan at the time - was given a rather low priority rating by the population.

The paper is structured as follows. The next section provides background information on Cali, including how city developments fit into the national urban picture. Section 3 describes the survey instrument used. Section 4 highlights some of the results of the survey of particular relevance to city policy makers. Section 5 concludes.

\section{The Setting: Developments in Cali, Colombia}

Cali, with over two million citizens the second largest city in Colombia, is the capital and economic hub in its departamento, the Valle del Cauca. Cali's GDP was around 6 billion dollars at the end of the 1990s, representing 7\% of national GDP and accounting for more than half of GDP of the department. The most important sectors in 1998 were manufacturing (25 percent of city GDP), communal services (22 percent), real estate services (15.9), financial services (11), construction (11), and commerce (9). The city population grew rapidly throughout the 1990s and continues to do so today with a large number of migrants fleeing political and drug-related crime in the rural areas.

Administratively, Cali's metropolitan area is divided in 21 urban comunas (where 94 percent of the population live) and 4 rural comunas. Decentralization in Colombia increasingly shifts implementation of programs from municipal governments to comunas but broad expenditure and revenue policy is still largely determined by the municipal government and legislature (the Municipal Council). Over two-thirds of Cali's revenues stem from local taxes 
with central government transfers accounting for the rest (Solans 2000). ${ }^{1}$ The national government transfers are conditional funds that can only be used for specific purposes, such as health, education, or housing.

Cali and the Valle de Cauca were one of the hardest hit regions in the economic recession in Colombia in the second part of the 1990s. The recession in Cali was partly linked to a national economic downturn and also attributable to the crack-down on drug trafficking within the city, which reduced income and wealth considerably - money which used to fuel the local economy, especially the construction sector and local merchandise. Agriculture, construction, manufacturing and the public utilities sectors recorded negative real growth rates from 1995 onward (Urrea and Ortiz 1999, Annex 8).

While the city was in deep recession at the end of the 1990s, the hands of the municipal government to counter the national economic trend were tied. The city hit its indebtedness limits at the beginning of 1997 and faced the tough situation of having to reduce real expenditures due both to high debt payments and lower tax revenues. The possibility of starting an expansionary, counter-cyclical fiscal policy were hence limited.

Social indicators show how the city recession impacted the lives of the population. Table 1 contains unemployment, inequality and child labor statistics for the five largest Colombian cities in 1994 and 1998. Cali was the only large city in Colombia that recorded an increase in income inequality over this time period of economic decline. Open unemployment in Cali grew by 8.4 points and affected almost one out of every five Caleños in the labor force in 1998, significantly higher than in other large cities in Colombia. With the economic recession came also a rise in informality (and hence reduced access to formal social security and health care; Santamaria 1999, p.21) and child labor. In 1998, urban crime rates were at a high in Cali with a homicide rate of 80 per 100,000 inhabitants. $^{2}$

1 During the 1990s, tax revenues in Cali increased rapidly, outpacing the inflation rate. In 2000, personnel expenses made up about 80 percent of total expenses (excluding debt service; Solans 2000).

2 Different geographic areas in the city showed varying patterns of crime. Youth gangs, some of them operating under guerilla influence or organized crime, assumed a prominent role in conducting the crimes (Martin 2000). 
Table 1: $\quad$ Social Indicators for Cali and other Colombian cities, 1994 and 1998

\begin{tabular}{|c|c|c|c|c|c|c|c|c|c|}
\hline & \multicolumn{3}{|c|}{ Unemployment } & \multicolumn{3}{|c|}{ Inequality ${ }^{1}$} & \multicolumn{3}{|c|}{ Child Labor (12 to 16 years, } \\
\hline & 1994 & 1998 & Change & 1994 & 1998 & Change & 1994 & 1998 & Change \\
\hline Bogota & 4.9 & 14.8 & +9.9 & .55 & .54 & -0.01 & 8.1 & 7.7 & -0.4 \\
\hline Medellin & 8.6 & 16.7 & +8.1 & .58 & .51 & -0.07 & 7.5 & 6.6 & -0.9 \\
\hline Cali & 11.3 & 19.7 & +8.4 & .51 & .54 & +0.03 & 7.9 & 9.1 & +1.2 \\
\hline Barranquilla & 10.1 & 13.0 & +2.9 & .76 & .57 & -0.19 & 6.1 & 5.9 & -0.2 \\
\hline Bucaramanga & 8.0 & 15.9 & +7.9 & .48 & .48 & 0 & 15.8 & 14.9 & -0.9 \\
\hline Total Urban & 7.4 & 15.7 & +8.3 & .58 & .55 & -0.03 & 8.2 & 8.4 & +0.2 \\
\hline
\end{tabular}

$1 \quad$ Inequality is defined by the Gini coefficient

Source: $\quad$ Santamaria (1999) based on Encuesta Nacional de Hogares by DANE.

Poverty and misery increased strongly from 1994 to 1998 . According to an evaluation of the National Household Surveys from June 1994 and 1998, Urrea and Ortiz (1999, p.22-24) find that poverty in the city increased from $29.8 \%$ to $39.0 \%{ }^{3}$ while the percentage of the city population in misery - defined as not even able to purchase a basic basket of food - doubled and rose from 5.3 percent to 10 percent. In 1998, more than 800,000 people lived in poverty in the city and more than 200,000 in misery.

Table 2: $\quad$ Poverty and Misery in Cali, 1994 and 1998

\begin{tabular}{|c|c|c|}
\hline & 1994 & 1998 \\
\hline \multicolumn{3}{|l|}{ poverty } \\
\hline headcount rate $(\%)$ & 29.8 & 39.0 \\
\hline absolute number ('000) & 571 & 807 \\
\hline \multicolumn{3}{|l|}{ misery } \\
\hline headcount rate $(\%)$ & 5.3 & 10.0 \\
\hline absolute number ('000) & 101 & 207 \\
\hline
\end{tabular}

Source: Urrea and Ortiz (1999, p.22-23).

Against this background, Cali launched a new effort to formulate a city development strategy in $1999 .{ }^{4}$ Regarding the goal of policy makers to reduce poverty in the city, a number of key questions emerged which needed to be answered in the run-up to such strategy formulation:

Urrea and Ortiz (1999) use the nationally defined poverty line from the Colombian statistical institute DANE.

This was one in a continuum of efforts of the city to define it's long-term development plan. For example, the city's development plan (1998 to 2010) made social investment and citizen's participation priorities in the local management agenda, with the explicit objectives of achieving equal access to opportunities for the integral development of the population. Departmental plans for the period 1998 to 2001 set out specific targets and goals for education, health, housing and social welfare. Within the investment plan, one project stood out: the metro. The light rail system was estimated to cost US\$707 million (municipal costs would have been 31.5 percent; national government costs 68.5 percent). 
(i) What were the most prominent characteristics of poverty in the city? How was poverty distributed spatially? Did the prolonged crisis produce hunger? What were the main characteristics of unemployment?

(ii) How were municipal expenditures in key areas (infrastructure, social sectors) distributed geographically? Did they benefit the poor (and poor areas) over- or under-proportionally?

(iii) How did the poor (and non-poor alike) rate the quality of municipal services which are key to reducing poverty (health, education, water, sanitation, garbage collection, electricity)?

(iv) What were the main priorities of the poor for municipal programs? Did these priorities differ from non-poor groups? Specifically, did the poor also view the large planned outlays for public transport (the metro system) as a major investment priority for the city?

These questions were to be answered by a specially designed and fielded city survey.

\section{The Instrument: A Rapid City Survey for Cali}

\subsection{City Surveys}

In urban planning, a rich tradition exists to employ random sample, representative city surveys to examine research and policy questions in sectors such as health, environment, housing, water, electricity, transport, and urban livelihoods. We can classify city surveys in three broad groups: those seeking to quantify specific variables of interest; those analyzing qualitative perceptions and priorities of the population; and those monitoring welfare developments over time.

Probably the most common use of city surveys is to quantify specific variables of interest. For example, Gupta and Baghel (1999) quantify the levels and differentials of infant mortality in Calcutta and Raipur City. Swait and Eskeland (1995) examine travel modes based on an urban travel survey in Sao Paulo. Or energy use patterns are examined by Alam et al (1998) in Hyderabad, India. Similarly, city surveys have been extensively applied to examine urban housing market characteristics in both developing country cities (Benjamin et al. 1987, Gouh 1998, Kaitilla and Sarpong-Oti 1993) as well as developed country 
conglomerates. The New York City Housing and Vacancy Survey, for example, can be used to examine patterns and predictors of housing turnovers of different ethnic groups (Rosenbaum 1992). Data collected can then lend itself also to study social behaviors. Borrell et al (2000) use the Barcelona Health Interview Survey to examine social class inequalities in health related behaviors like tobacco and alcohol consumption

Second, city surveys are also key instruments to learn about priorities and perceptions of the population. Jacobi (1994) employs a survey to understand environmental problems at the household and neighborhood level and the respondents' perceptions with regard to the nature and cause of these problems and best means for their resolution in Sao Paulo. Similarly, Mensah and Whitney (1991) capture perceptions associated with public and domestic refuse and its disposal and their relationships with gender, educational level, and ethnicity in a West African city. They are also used to examine transport priorities in Bejing (Wei 1998) and to record satisfaction levels with the whole array of public services provision in Bangalore (Paul 1998).

Lastly, several city surveys are designed to measure (and monitor) welfare levels of the population while combining such assessment with the subjective evaluation of the population about changing living standards. Such city surveys have been applied repeatedly in St. Petersburg (Protassenko 1997) and in Bloemfontein, South Africa (Beukes and van der Colff 1997).

\subsection{The Cali Survey}

Given the information requirements for the development of the city strategy, we decided to field a specialized city survey in Cali. The alternative to fielding a specialized survey would have been to rely on information available from the national household survey (Encuesta National de Hogares, EHO) conducted periodically by the statistical institute DANE. As for four other cities in Colombia, the EHO was representative at the city level with a sample of roughly 500 households interviewed per survey round. However, the Encuesta National was quite limited in scope and concentrated on measuring income, employment and housing conditions with some, but limited, education information captured as well. Since not specifically focused on Cali, it did not examine access to specific city programs nor population perceptions and priorities for future city policies. Further, it was only representative at the city 
level and did not allow for the examination of poverty and welfare levels at lower administrative levels. Therefore, we decided to develop and field the 'Service Access and Perception Survey in the Municipality of Cali' or Encuesta De Acceso y Percepcion de los Servicios Ofrecidos por el Municipio de Cali (EPSOC).

The requirements for the EPSOC survey were multiple. First, apart from providing a basic poverty profile for the city, it had to answer the specific policy questions on the characteristics of poverty, the distribution of city resources, satisfaction with public services delivery, and priorities for budget decisions. It was hence required to collect both quantitative and qualitative data. Second, the sample had to be large enough to provide reasonably good estimates of poverty and social characteristics at sub-city levels. Third, data collection and analysis had to be rapid as the City Development Strategy formulation was on a very tight time schedule (linked to political necessities in Cali). Fourth, it had to be affordable as it was to be a pilot for the municipality with a potential to be conducted and financed by the city itself in the future.

The final EPSOC survey instrument consisted of nine different modules. With comments from many local organizations, we designed and planned the questionnaire in close cooperation with the Centre on Socio-economic Research and Documentation of the Universidad del Valle in Cali. ${ }^{5}$ The household module collected information pertaining to size, composition, function (headship), gender, civil status and origin of all household members. The housing and living condition module recorded housing material and space, basic service supply (including Cali-specific questions on access to garbage disposal), service satisfaction levels, ownership arrangements as well as consumer goods possession. An extensive education module included questions on literacy, school attendance (by type of school), highest school degree and year obtained, as well as private educational costs. But it also asked about problems in the schools, reasons for absenteeism, and overall satisfaction levels of students. Similarly, the health module recorded both the standard information about illness patterns, health service utilization (including birth attendance, pre-natal care provision), and health insurance access as well as satisfaction levels (and reasons for dissatisfaction) with the health service provision. A nutrition and childcare module inquired about access to, and satisfaction with, assistance programs, distinguishing a number of public, private and

$5 \quad$ Although the survey included many questions specific to the social situation in Cali, it did build significantly on similar surveys conducted in other cities including a survey fielded in parallel in Kampala, Uganda (see Nord (2002) for a description and use of the Kampala survey). From the Universidad del Valle, the major collaborators where Fernando Urrea and Carlos Ortiz. 
community-based providers. Similarly, a transport section aimed to establish user and access patterns to public transport as well as contentment for their use.

The labor market module included questions as to economic activity of all household members (by sector and firm), formality of labor contracts, time worked, and search behavior for employment, as well as several questions on household earnings from work and transfer incomes. The sample population interviewed were asked about their budget priorities ${ }^{6}$ for the city in two ways: what programs they would suggest to be expanded under a budget increase and what programs (of an identical list) should be cut if the need were to reduce the overall city expenditures. A civic participation module aimed to assess the degree of participation in local organizations, ranging from Cali-specific 'Juntas de Administration Local' to community self-help groups, NGOs and sports clubs. Reasons for participation/non-participation, willingness of interviewees to become active in specific programs, as well as willingness to participate financially in service provisions were explored.

The survey covered 1,912 households (8,461 individuals) in the city, being representative of five areas and socio-economic strata as defined by the Colombian statistical institute DANE. The sample frame used was that of the last Colombian census (1993) which was updated with the latest local area population estimates which the statistical institute provided. Based on that sampling frame, area selection and determination of the number of households per area was designed so that representative results could be drawn for socioeconomic strata as well as by geographical areas. Sampling, digitalization (using double entries to provide immediate consistency checks during the data entry process), data cleaning as well as basic tabulation was carried out by an experienced Colombian survey firm. The definition of socio-economic strata followed the definition of DANE.

The survey has elements of contextual as well as non-contextual data collection instruments $^{7}$ and in such draws on elements of in-depth multi-topic surveys (like the Living Standard Measurement Surveys ${ }^{8}$ ), rapid monitoring surveys like the Core Welfare Indicator Questionnaire $^{9}$ and village surveys. It is contextual in the sense that it was developed to capture the specific economic, social and economic environment of the municipality of Cali. It did not, however, employ open-ended questions but used standard, pre-formulated questions

$6 \quad$ The list of programs included all those for which the municipality had a full or partial implementation mandate. The list comprised education, health, public transport, water supply, garbage collection, sanitation, public lightening, childcare, polices, social housing, sport arenas, and public works programs

See Booth et al (1998) and Hentschel (1999).

See Grosh and Glewwe (1999) and the Living Standards Measurement Study website (www.worldbank.org/lsms/). 
and answers. At the same time it was designed to be a mixture of an opinion and evaluation survey (since it collected substantial amounts of qualitative information) and a quantitative data collection instrument.

Duration and costs of the survey were well within expectations. Total time for sampling (including the update of an existing sampling frame), data collection, digitations and cleaning amounted to ten weeks (from beginning August 1999 to October 15, 1999). After several weeks of analyzing the data and drafting a report on poverty and social conditions, we were able to present the major findings in a large seminar in Cali at the beginning of December so that total turnover time was relatively short. Total cost of the survey was moderate. Not including the analysis, the total cost of the survey (including questionnaire design, sampling, data collection, digitations) was well below US\$40,000. ${ }^{10}$

\subsection{Household Welfare Definition}

While the survey was not intended to provide new estimates of absolute poverty levels in the city, we nevertheless needed to distinguish different welfare groups in the population to answer the questions posed. Inclusion of a very detailed income or expenditure module would have increased length of the questionnaire and survey costs considerably. Further, there was no demand in the city for re-estimating absolute poverty levels as Urrea and Ortiz (1999) provided such measurement using detailed income information and a poverty line approach based on the pricing of a minimum nutritional basket. But to answer questions about expenditure distribution and priorities in the city, the survey needed to allow for welfare distinctions between households.

Based on the income questions included in the labor market module, we used household per capita income as the welfare indicator for the purpose of the analysis. While not as comprehensive as in Living Standard Measurement Surveys, the module did distinguish several income sources for all household members: wages and salaries of primary and secondary occupation (by unit and frequency of payment), additional income from work, interest income, rental income, pensions, transfers, and other income sources. ${ }^{11}$ Aggregating

See the homepage of the Core Welfare Questionnaire (http://www.worldbank.org/afr/stats/cwiq.cfm).

The survey was financed by the Bank-Netherlands partnership program whose support is gratefully acknowledged.

We encountered, however, that the data base did not include wage and salary income for about one third of informants who worked during the time period of the survey. For these, we constructed a simple estimation model of hourly wages 
all family incomes and dividing by the number of members in the household provided us with household per capita income which we used to construct income quintiles for the population of Cali. $^{12}$

Based on the income per capita estimation, households were grouped into population quintiles. Further, for the purposes of this study, we defined poverty to be the bottom two income quintiles comprising 40 percent of the city population (following the result of Urrea and Ortiz, 1999). Similarly, we defined extreme poverty to constitute the bottom 20 percent of the population.

\section{Quantitative and Qualitative Results}

\subsection{Some Characteristics of Poverty}

Given that the EPSOC included an income module which allowed the ranking of households according to their welfare level, simple cross-tabulations between income quintile and key characteristics of living conditions allowed development of a detailed profile of poverty and welfare in the city. Such a profile can help in understanding common as well as distinguishing factors between population groups relating to service access, educational attainment, labor market characteristics and so on. Many of the poverty correlates derived from the survey confirmed earlier work, especially relating to the correlation between household welfare and (i) service access (universal access to electricity but high dependence of poorer households on shared use of public water and sanitation services), (ii) years of formal schooling of the household head (strong relations between formal schooling and welfare), (iii) school enrolment rates (57,000 girls and 44,000 boys not enrolled in primary school) (iv) gender of the household head (little differences across welfare quintiles), (iv) shelter (close to 300,000 people lived in houses without a proper title - 60 percent of whom were poor), or ( $\mathrm{v}$ ) crime (relatively little difference in incidence of experiencing crime across income groups but geographical concentrations in certain comunas). But the analysis of welfare characteristics caught the attention of policy makers and academics/civil society alike with respect to four findings: first, the nexus between the labor market, education and poverty;

as a function of individual (education, experience, gender), occupational, and area characteristics to impute the missing data. 
second, the incidence of hunger; third, the low coverage rate of targeted health subsidies; and fourth, geographical aspects of poverty in the city. Table 3 includes a few sample tabulations of these latter variables for illustrative purposes. ${ }^{13}$

Labor Market. The survey provided ample information on the link between the labor market and poverty in the city. Unemployment rates of the poorest income group were found to be around 40 percent; the working age population of whole barrios in the poorest parts of town was forced to be idle and youth unemployment was at exorbitant levels. For the large majority of the poorest income groups, employment was only available in informal jobs, defined here as those without formal contracts and/or without access to social security. More than 70 percent of the employed population of the poorest income group were without formal employment contracts and only 13 percent of them had access to social security. Breakdowns of the pattern of unemployment revealed that it impacted somewhat more on men than women; that it was especially a phenomenon of the young; and that it was, surprisingly, especially those young people with a completed secondary and incomplete university education that were at the highest risk of becoming unemployed. This pointed to an important mismatch between the contents and quality of secondary education and the skill demands of the labor market.

Since the survey collected quite detailed data on hourly earnings of those employed, it did allow us to estimate earnings equations to assess segmentation of the labor market and rates of returns to schooling. ${ }^{14}$ We found that, all factors held equal (like experience and years of education), a significant gender discrimination existed with women earning 17 percent less than equally qualified, educated and experienced men. Further, an 'area' effect played an important role in wage formation as workers from the wealthiest districts in the city were able to earn a 30 percent premium compared to workers living in the other, poorer parts of town. This was possibly attributable to a stigma or social class effect - or it might have also reflected differences in the quality of education across town. We found that primary schooling had a comparatively good return with every year of primary schooling increasing expected earnings by about 9 percent. But private returns to secondary schooling were considerably lower (at 6.5 percent), supporting the link between unemployment and

12 In dividing total household income by household size, we assumed that no economies of scale in consumption exist. Testing for variation in the household economies of scale did not produce significant shifts in the poverty profile (see Lanjouw and Ravallion 1995 for a discussion).

13 For a complete discussion of the Cali poverty profile, see World Bank (2002).

14 We estimated a Minceranian equation in which the log of hourly wages was regressed against individual and household characteristics (like education, age, gender, type of occupation, area of residence etc.). 
secondary education discussed above. Returns also differed with age: For the younger working population below 35 years of age we found that all returns were several percentage points lower than for the working population older than $35 .^{15}$

Incidence of Hunger. The survey also revealed a characteristic of poverty which had not been much on the radar screen of public debates before: poverty went hand in hand with food insecurity - and the degree of such insecurity was at alarming levels in Cali in 1999. As reported in Table 3, about one-third of the population in the poorest income quintile had family members having been hungry at least once over the past year while not commanding the financial resources to purchase food. And a full 60 percent of poor parents stated that they had to reduce nutrition for their children because of insufficient resources (over a one year period). Even though these figures might have been somewhat upward biased, the results pointed to a serious problem of food insecurity among the poorest of the poor in Cali. ${ }^{16}$ This is especially worrisome as the reach of nutrition programs was extremely small. Only 4.4 percent of the poorest population group reported having access to food aid.

Health Care and Insurance. The EPSOC survey showed that the poor had a higher demand for health care than better-off income groups. The poorest income quintile had a selfassessed rate of illness of around 30 percent (over a period of six months); the wealthiest population quintile of about 20 percent. Poorer families were much more likely to seek help in public health centers or hospitals while private doctors and clinics emerged as the preferred providers for better-off families. For many of the poor such visits cut into the family budget deeply since only half of them held any form of health insurance. While the system of beneficiary identification SISBEN was well-targeted (i.e., it reached a much higher proportion of the population in income quintile 1 than in income quintile 5), its coverage was relatively low. Only 22 percent of the poorest population reported to have access to the SISBEN network - and with it to subsidized health services. Access to private and public health insurance like the Instituto de Seguridad Social (ISS) and the Empresa Privada de Salud (EPS) was low for the poor and much higher for the better off.

\footnotetext{
15 One caveat of such estimates exists, however. They are calculated only for the occupied population and hence do not take the unemployed into account. Hence, average returns over the whole labor force (employed and unemployed) are likely to have been lower. thought that answering 'yes' to food insecurity questions would have given the household a chance to access subsidy programs.
} 
Geographical distribution of poverty. In Cali, as in Colombia in general, much of the geographic discussion of poverty is framed along 'strata' lines. These are definitions of socioeconomic groups, drawn up largely from census information and including mainly information on unsatisfied basic needs based on housing characteristics (material of the house, access to services etc.). Strata are defined at the manzana-level which generally includes one complete block of houses (four sides). Differences in housing and basic service characteristics within a manzana can hence not be picked up. Strata definitions in Colombia play an important role since subsidy programs are targeted according to such information and most public services are charged differentially according to strata as well.

Table 3: Some Characteristics of Income Poverty, Cali, 1999 (percent)

\begin{tabular}{|c|c|c|c|c|c|c|}
\hline & \multicolumn{5}{|c|}{ Income Quintile } & \multirow[b]{2}{*}{ Total City } \\
\hline & 1 & 2 & 3 & 4 & 5 & \\
\hline \multicolumn{7}{|l|}{ labor market } \\
\hline unemployment rate & 35.9 & 22.4 & 18.4 & 11.8 & 5.8 & 17.1 \\
\hline - male & 35.7 & 24.6 & 18.4 & 12.9 & 6.4 & 18.0 \\
\hline - female & 36.1 & 18.8 & 18.5 & 10.0 & 5.0 & 15.9 \\
\hline - all $14-24$ yrs olds & 51.8 & 34.8 & 27.7 & 21.7 & 19.7 & 30.3 \\
\hline informal empl.: w/o contract & 71.2 & 51.7 & 46.8 & 39.5 & 26.7 & 42.3 \\
\hline $\begin{array}{l}\text { informal empl.: w/o social security } \\
\text { food security }\end{array}$ & 84.4 & 65.5 & 67.8 & 58.0 & 43.8 & 59.8 \\
\hline Family member $w /$ hunger $^{2}$ & 34.2 & 22.8 & 16.9 & 11.7 & 5.1 & 18.1 \\
\hline Had to reduce food intake & 60.6 & 53.6 & 42.7 & 25.7 & 12.9 & 42.4 \\
\hline $\begin{array}{l}\text { Access to nutrition prog. } \\
\text { health }\end{array}$ & 4.4 & 3.7 & 3.1 & 1.9 & 0.5 & 2.7 \\
\hline $\begin{array}{l}\text { Sick in last } 4 \text { months } \\
\text { when used medical facility }\end{array}$ & 28.9 & 24.3 & 26.6 & 21.3 & 19.3 & 24.1 \\
\hline - Public health post & 37.6 & 29.1 & 27.7 & 13.6 & 7.5 & 22.7 \\
\hline $\begin{array}{l}\text { - Public hospital } \\
\text { Health insurance }\end{array}$ & 21.1 & 16.1 & 16.9 & 8.8 & 8.9 & 14.2 \\
\hline$-I^{2} S^{3}$ & 13.8 & 19.6 & 26.3 & 27.2 & 29.4 & 23.3 \\
\hline$-E^{-S^{4}}$ & 13.2 & 22.9 & 20.2 & 36.4 & 41.4 & 26.8 \\
\hline - SISBEN ${ }^{5}$ & 22.7 & $12 . .2$ & 10.9 & 4.8 & 0.8 & 10.3 \\
\hline $\begin{array}{l}\text { - not affiliated } \\
\text { geographical areas (distribution) }\end{array}$ & 46.0 & 41.2 & 39.2 & 26.9 & 17.6 & 34.2 \\
\hline Strata 1 (low-low) & 30.4 & 28.8 & 20.0 & 15.5 & 5.4 & 100 \\
\hline Strata 2 (low) & 23.8 & 24.9 & 24.1 & 16.4 & 10.9 & 100 \\
\hline Strata 3 (medium-low) & 14.5 & 15.9 & 22.1 & 25.7 & 21.8 & 100 \\
\hline Strata 4 (medium) & 13.4 & 8.7 & 9.7 & 23.6 & 44.6 & 100 \\
\hline Strata 5 (medium-high) & 5.6 & 5.3 & 3.5 & 14.5 & 71.2 & 100 \\
\hline Strata 6 (high) & 5.6 & 3.5 & 7.1 & 18.5 & 65.2 & 100 \\
\hline
\end{tabular}

$\begin{array}{ll}1 & \text { Mean education years for the whole population } 18 \text { years and older. } \\ 2 & \text { in the past year. } \\ 3 & \text { ISS: Instituto de Seguridad Social de Colombia } \\ 4 & \text { EPS: Empresa Privada de Salud } \\ 5 & \begin{array}{l}\text { SISBEN: Selección de Beneficiarios de Programas Sociales. SISBEN is not a program per se } \\ \text { but a system that allows identification of the eligible population for subsidized social programs. }\end{array} \\ 6 & \text { Distribution of strata by quintile, totaling to } 100 \text { percent per strata. }\end{array}$

Source: Own calculations from EPSOC (1999). 
The EPSOC allowed us to examine the relationship between the strata categorization of households and income per capita as an alternative welfare measure. Differences between the two could arise for two reasons: first, a less than perfect correlation between income per capita and the strata classification; second, considerable heterogeneity of living standards within manzanas and the 'average' living standard not being meaningful at the individual, household level. Indeed, income and strata showed a relatively high variation. Based on the EPSOC, Table 3 includes a mapping of the strata (row entries) by population income quintiles. Variation of strata by income is very high, especially for stratas two and three - in strata three, income is almost evenly distributed across all quintiles. This result cautioned against using strata as the only identifying variable for geographic targeting of beneficiaries, especially when aimed to reach income-poor households.

We were also able to compute the distribution of poverty within the city. Originally, sampling for the EPSOC was designed to achieve representativeness for five different areas within the city. ${ }^{17}$ However, poverty within these larger areas varied significantly so that we also derived poverty rates at the individual comuna levels. Since this considerably reduced the number of observations available per geographic unit, it lowered precision of the poverty estimates and hence made it even more important to calculate the standard errors associated with each of the poverty rates. Results are presented in Table 4. As can be seen, the standard errors were in a reasonable range except for comunas 3,4 and 12. Consequently, extreme caution was warranted for city policy makers to draw conclusions on poverty in these three comunas.

We found that poverty varied significantly within the five larger areas generally used for analysis within the city - and that heterogeneity even within comunas was also considerable. Several comunas (especially 7 and 13) showed very high extreme poverty rates but rather average poverty rates, indicating that pockets of extreme poverty in these comunas existed. ${ }^{18}$ The existence of such pockets of extreme income-poverty within comunas calls for a good

17 The selection of the five geographic areas, for which the sample was to be representative, followed a commonly used classification in Cali. First, the poor area in the East of the city is referred to as Aguablanca (comunas 13, 14, 15 and 16). Twenty years ago, Aguablanca did not exist and in its place was a large lake. But with massive migration from the rural countryside, the lake was drained and slum-settlements were set up and slowly upgraded. The comunas of Aguablanca have been heavily populated by black migrants from the pacific coast. The second area commonly identified as very poor is ladera, comprising comunas 1, 18, 20 (and 21) in the western part of the city. Most of these comunas are steeply sloped at the hill side and comprised of mainly poorer mestizo migrants. The comunas in the north-eastern part of the city $(6,7)$ also include recent migrants and are mostly populated by the lower-middle income class. Lastly, a corredor which runs from the north (comuna 2) through the center (comuna 19) to the south (comuna 17) are populated by the mediumand higher-income class are consequently show relatively low levels of poverty. 
and extensive information system that allows the municipality to channel resources to these especially poor neighborhoods.

Table 4: Poverty Headcount Rates ${ }^{1}$ by Comunas, Cali, 1999

\begin{tabular}{|c|c|c|c|}
\hline Comuna & Headcount Poverty & Headcount extreme poverty & Contribution to Total Poverty \\
\hline 1 & $54.5(6.71)$ & $14.7(4.77)$ & 2.8 \\
\hline 2 & $15.3(2.11)$ & $11.8(1.89)$ & 1.7 \\
\hline 3 & $42.0(8.34)$ & $19.5(6.70)$ & 2.4 \\
\hline 4 & $45.3(10.61)$ & $14.6(7.53)$ & 1.5 \\
\hline 5 & $19.0(4.53)$ & $10.9(3.60)$ & 2.6 \\
\hline 6 & $51.2(4.47)$ & $23.4(3.79)$ & 9.4 \\
\hline 7 & $47.3(4.99)$ & $31.8(4.66)$ & 8.8 \\
\hline 8 & $31.2(4.88)$ & $11.3(3.34)$ & 4.8 \\
\hline 9 & $22.4(4.81)$ & $12.2(3.78)$ & 3.1 \\
\hline 10 & $25.9(4.28)$ & $12.9(3.27)$ & 4.1 \\
\hline 11 & $36.2(4.93)$ & $15.8(3.74)$ & 7.0 \\
\hline 12 & $28.9(10.14)$ & $17.3(8.46)$ & 1.3 \\
\hline 13 & $42.9(4.52)$ & $27.0(4.05)$ & 6.4 \\
\hline 14 & $72.8(3.63)$ & $37.0(3.94)$ & 15.9 \\
\hline 15 & $55.7(5.55)$ & $32.7(5.24)$ & 6.0 \\
\hline 16 & 55.4 (3.99) & $24.2(3.44)$ & 7.7 \\
\hline 17 & $6.7(3.37)$ & $3.7(2.55)$ & 0.4 \\
\hline 18 & $53.1(5.12)$ & $26.4(4.52)$ & 7.3 \\
\hline 19 & $19.9(2.95)$ & $7.8(1.98)$ & 3.4 \\
\hline 20 & $45.7(6.72)$ & $15.3(4.85)$ & 3.4 \\
\hline
\end{tabular}

$1 \quad$ The poverty lines were endogenously defined as those providing a 40 percent poverty and a 20 percent extreme poverty rate in the city. Standard errors are in parentheses Source: $\quad$ Own calculations from EPSOC (1999).

Using the geographical information on poverty, we derived two poverty maps (figures 1 and 2). While poverty rates by comuna are important (figure 1), of equal importance is the geographical distribution of the poor (figure 2). Since comunas varied widely in size - from 61,000 in comuna 4 to 254,000 in comuna 14 -- these two angles of looking at the same picture showed different results. Visually, map 2 shows the distribution of the poor population in the city with the size of the circles indicating the size of the poor population group in the respective comuna. While by far the largest amount of poor people also lived in the comuna with the highest poverty rate (comuna 14 with about 185,000 poor people), a comparison of the maps also shows important differences, e.g. for the ranking of comuna 11 (moderate poverty rate but large population) or comuna 1 (high poverty rate, low population).

Closely linked to the spatial distribution of poverty in the city were a number of population characteristics. First, the comunas with the highest headcount poverty rates were also the comunas with the most rapid population growth rates in the last decade - which also explains why the share of the migrant population was highest in these 

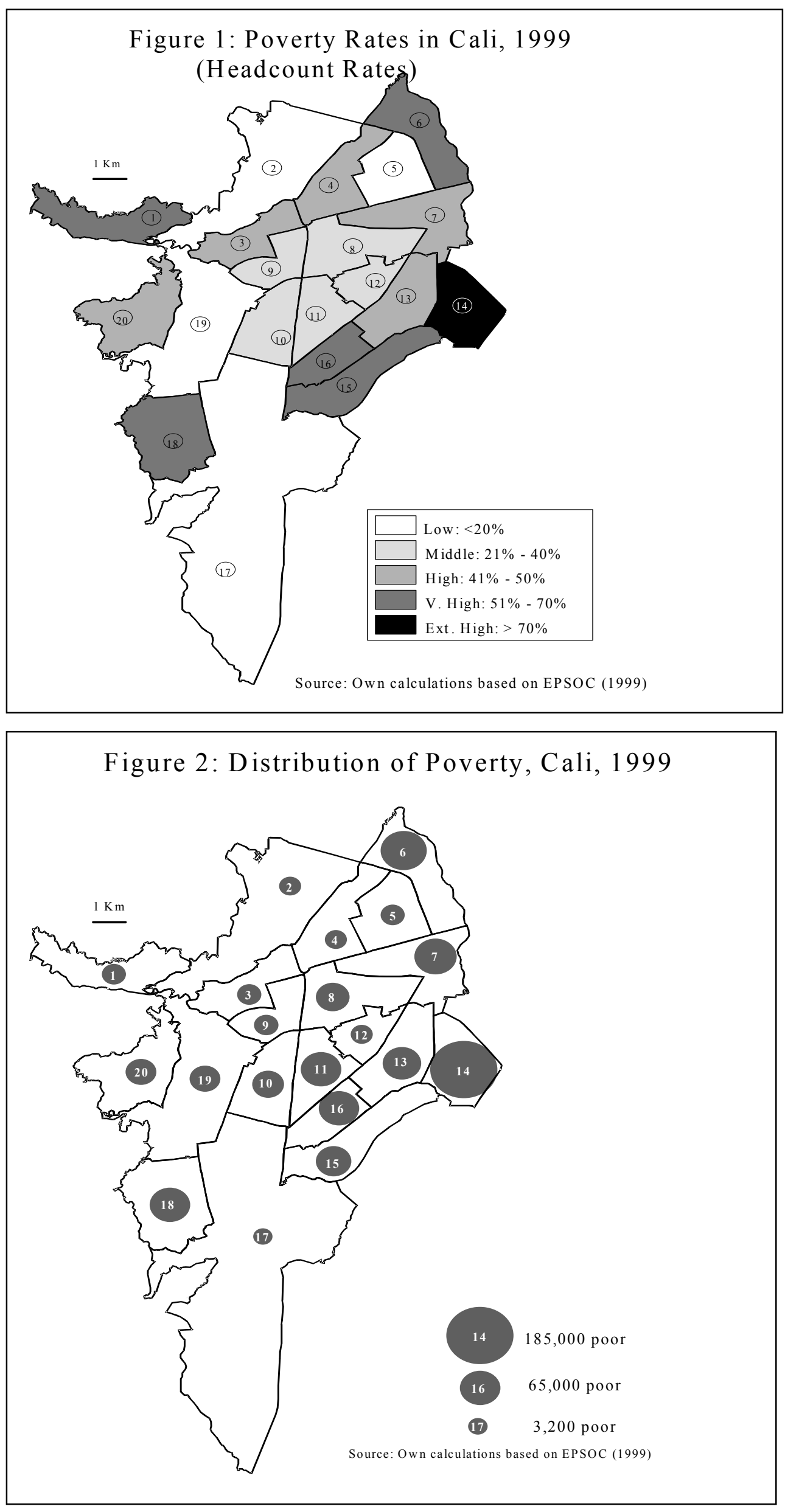
comunas. $^{19}$ Second, in the rapidly expanding comunas, the population density was highest crowding and congestion were the consequences. Third, poverty had a clear racial connotation in Cali - while the black population makes up about one-third of the overall population, they represented more than half of the poor. The black population is heavily concentrated in comuna 14. Lastly, high levels of homicide were concentrated in the most marginalized neighborhoods in the city.

\subsection{Incidence of Municipal Expenditures}

We now turn to an analysis of municipal expenditures in the city, which was one of the key questions the EPSOC was to answer. Who benefited from these municipal expenditures? And how were they distributed within the city?

At the end of the 1990s, by far the largest share of municipal expenditures in Cali went to servicing the city debt; social expenditures in health, education, pacification and social welfare were a distant second. Of total municipal expenditures, only 26 percent benefited the population in individual comunas as -- in addition to the debt service - the municipal administration absorbed a large part of the available resources.

These geographically targeted expenditures, however, went largely to the better off comunas. We examined the spatial distribution of expenditures in three categories: pacification, education, health, sports, social housing); transport (roads, maintenance, transit) and all social expenditures (social welfare,

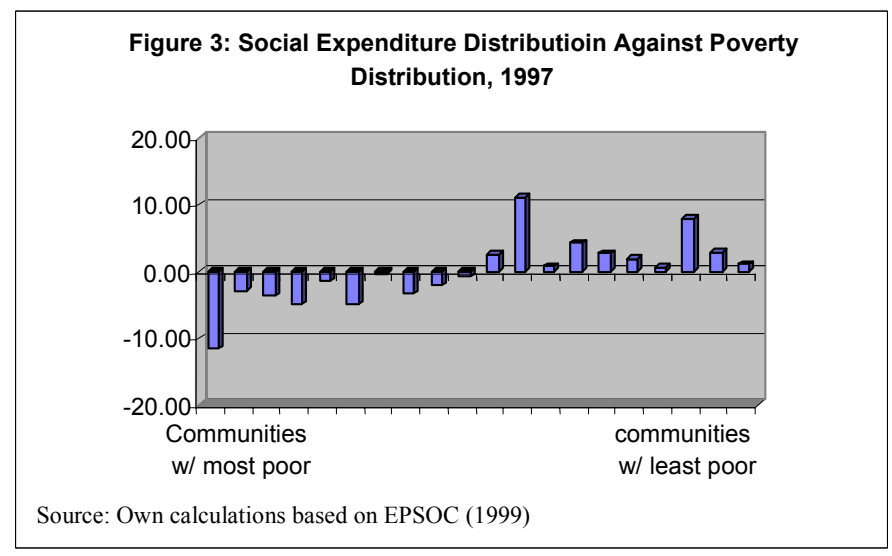

other expenditures. Figure 3 compares the distribution of the social expenditures against the distribution of the poor in the city. That is, we calculated the share of social expenditures flowing to a specific comuna and subtracted from this the share of the total poor living in the same comuna. A positive bar will hence signal that the comuna obtained a higher share of expenditures than it would have obtained had expenditures been distributed strictly according to a poverty map. In the figure, comunas are ranked from left to right by the share of the poor

According to Urrea and Ortiz (1999, p.7) the population growth rate from 1993 to 1998 has been the highest in comunas 
- the better off the comuna, the further it is situated to the right in the figure. The figure shows negative bars towards the left (the poorer comunas) and positive values to the right (the better-off comunas). Hence, the spatial distribution of social expenditures in Cali was antipoor and perpetuated spatial inequalities. The same result emerged when examining other expenditure categories.

Obviously, the criterion applied here is a very strict one: it implies that the spatial distribution of expenditures would ideally follow the distribution of poverty in the city. For many, especially bulky investments which benefit the whole city, this criterion will not be appropriate. However, an anti-poor bias emerged in all expenditure categories and this needed to be addressed for the city to become a more integrative and equal place for its inhabitants. One reason for the observed anti-poor distribution of city expenditures originated with the formula guiding comuna allocations. The first component of the formula distributed expenditures equally across comunas, irrespective of their population and poverty levels. The second component took into account the fiscal effort of the area, clearly creating a bias against poorer comunas. Only the third component, an assessment of housing needs, worked in favor of poorer areas.

For a select number of programs, we could use the EPSOC survey to compute the distribution of benefits by income group. In the absence of data on individual benefits of education or health services rendered, we made the common, but restrictive, assumption that 'access' was equal to 'benefits'.

Most public health and education expenditures in Cali were progressive. Table 5 reports that the largest share of public expenditures in these sectors benefited the poorest two income quintiles the most. Since the poor were the most intensive users of public primary and secondary education, a higher portion of the benefits of these expenditures flowed to them and the same held for public health centers and public hospitals. Although we had observed above that the coverage of SISBEN (providing access to subsidized social programs) was relatively small among the poor, ${ }^{20}$ benefits derived from being assigned to the system flew in a large proportion to the very poor - 43 percent to the poorest 20 percent of Caleños. Subsidies in higher education, however, went largely to the better-off income groups.

20 (7.2\%), $18(7.2 \%), 13$ through $16(2.4 \%), 6(2.4 \%)$ and $7(2.4 \%)$. coverage. 
Table 5: Distribution of Education and Health Expenditures in Cali, by income quintile, September 1999 (percent)

$\begin{array}{lrrrrrr} & \mathbf{1} & \mathbf{2} & \mathbf{3} & \mathbf{4} & \mathbf{5} & \text { Total } \\ \text { Primary education } & 32.9 & 30.5 & 21.8 & 9.3 & 5.6 & 100.0 \\ \text { Secondary education } & 23.4 & 25.7 & 21.7 & 18.8 & 10.4 & 100.0 \\ \text { University education } & 4.2 & 15.3 & 23.2 & 24.5 & 32.8 & 100.0 \\ & & & & & & \\ \text { Public health centers } & 31.0 & 24.9 & 25.1 & 11.9 & 7.1 & 100.0 \\ \begin{array}{l}\text { Public hospitals } \\ \text { SISBEN }\end{array} & 27.7 & 22.1 & 24.4 & 12.3 & 13.5 & 100.0 \\ \quad \text { Source: Own calculations based on EPSOC (1999). } & 44.2 & 23.7 & 21.2 & 9.3 & 1.6 & 100.0\end{array}$

\subsection{Service Satisfaction}

Access and distribution of city expenditures is one angle to look at municipal programs another angle is to see how their quality is rated. Part of the EPSOC survey was geared to obtain feedback from the population on satisfaction levels with municipal services in education, health and infrastructure provision. We were particularly interested to see whether the ratings of city services differed between the poor and non-poor populations.

As Table 6 reports, satisfaction levels varied significantly across services. Contrary to expectations, students attending school showed little dissatisfaction levels although a further breakdown revealed that dissatisfaction with public education (12 percent) was twice as high as dissatisfaction levels with private education (5 percent). Similarly, electricity, water and garbage collection were viewed as satisfactory by a large majority of the population. Health dissatisfaction - again especially of public services - was considerably higher with about onequarter of the population not content with the service being offered. Probed for why the public health service was not viewed as positive, most respondents listed long waiting times as the single most important inconvenient aspect. The city's sewerage service obtained similarly low ratings. And two-thirds of the population viewed as especially negative environmental cleanliness ('saneamiento'). This term included four components - regularity of (a) fumigation campaigns (against bacteria); (b) cleaning of public parks; (c) cleaning of public canals and tubes; and (d) cleaning of neighborhoods (streets and side-ways). Although all four aspects of such environmental cleanliness obtained negative ratings, dissatisfaction was clearly highest with the fumigation campaigns, across all regions of the city. 
Table 6: Dissatisfaction with Basic Social and Infrastructure Services, by income quintile, Cali, September 1999 (percent of population, by quintile)

\begin{tabular}{|c|c|c|c|c|c|c|}
\hline & 1 & 2 & 3 & 4 & 5 & average \\
\hline \multicolumn{7}{|l|}{ dissatisfaction with } \\
\hline - $\quad$ electricity service & 8.2 & 11.6 & 9.3 & 5.4 & 6.2 & 8.1 \\
\hline education (students) & 9.1 & 9.2 & 7.0 & 9.5 & 8.2 & 8.6 \\
\hline water service & 8.7 & 8.6 & 7.2 & 12.3 & 7.2 & 8.8 \\
\hline garbage collection & 9.2 & 7.7 & 10.1 & 12.8 & 11.2 & 10.2 \\
\hline health (those using them) & 24.7 & 16.2 & 17.9 & 16.0 & 17.5 & 18.4 \\
\hline sewerage & 33.8 & 23.1 & 21.9 & 26.0 & 20.1 & 25.0 \\
\hline environmental cleanliness & 61.2 & 66.8 & 60.5 & 64.3 & 60.9 & 62.7 \\
\hline
\end{tabular}

Source: Own calculations based on EPSOC (1999).

However, while dissatisfaction levels varied significantly across services, the EPSOC also showed that there was relatively little variation of ratings across income groups. Dissatisfaction with electricity, education, water and garbage collection was always significantly lower than discontent with health services, sewerage and environmental cleanliness. The variation of ratings across income groups is particularly important for the inclusiveness of city social policies: if, as seen here for Cali, the service ratings do not show a marked variation across income groups, it is possible for the city administration to focus on the needs of the poorest population group while at the same time meeting preferences of the other groups within the city.

\subsection{Budget Priorities}

It is of particular importance for the development of anti-poverty policies to understand the priorities of the poor - and to assess whether such priorities differ from the non-poor population. The EPSOC survey therefore included a module probing for such priorities. Tables 7 and 8 contain the results, again broken down by different income groups. Table 7 reports households' priorities of the type of program (of the 13 included in the table) that were to be expanded if the municipality had available resources. ${ }^{21}$ Table 8 then reports on the reverse scenario in which respondents had to choose one program for which they would suggest a reduction in municipal resources if this had to take place.

$21 \quad$ Respondents could only state one single preference. 
A clear pattern as to the priorities of the population emerged. If resources were available, education, health, employment generation and nutrition programs should be the beneficiary programs. In the reverse case (Table 8 ) these were exactly the programs which were to be protected from cuts. Instead, the interviewed population suggested expenditures for sports arenas, the police, public transport and lighting to be cut - all of these four areas also fared at the bottom of the list when an expansion of programs was probed. From the results obtained it was obvious that all population groups in Cali much preferred an expanded education and health system than an underground metro (a policy proposal that was discussed by the administration at the time the EPSOC survey was conducted). ${ }^{22}$

With few exceptions, priorities across income groups and regions were very similar as we had already observed above regarding the evaluation of city services. Social housing and nutrition programs fared somewhat higher on the list of priorities for the poor than for better off groups but overall differences in priorities were indeed small - which was a very positive result for social policy makers as the city population was not deeply divided among different alternatives in a scarce resource environment.

It is interesting to observe that priorities for municipal programs as shown in Tables 7 and 8 did not closely match with dissatisfaction levels of services reported above. One could hypothesize, for example, that education would not be the number one priority of families given that - overall - students were relatively satisfied with the service provided. But problem identification and priority articulation are indeed two different processes which need to be distinguished clearly. Identification of a problem, as related for instance to the sewerage service provided by the city, need not imply a subjective evaluation that investment in the service is more important than spending additional tax revenues on expanding a service which is rated as good. Further, when asked about spending priorities, respondents implicitly make an assumption about the efficiency of additional expenditures. Low efficiency expectaions of service provision could then explain why services with low satisfaction nevertheless obtain low budget priority ratings.

To sum up, problem identification through satisfaction ratings is important for the city to reform the services and, as such, can be a check on municipal performance. ${ }^{23}$ Priority budget identification, on the other hand, provides a wider picture on the relative evaluation of the

22 From a financial point of view, Solans (2000) comes to the same conclusion. 
importance of different programs and services, also taking into account how the public views the likelihood that additional investment would indeed improve service performance. Additional information would be necessary to understand household priority rankings independent of current delivery systems. In future applications of city surveys, it would be advisable to include such questions in the investigation.

Table 7: Municipal Programs: Priorities for Expansion of Programs, by income quintile, Cali, September 1999 (percent)

\begin{tabular}{lrrrrrr} 
& $\mathbf{1}$ & $\mathbf{2}$ & $\mathbf{3}$ & $\mathbf{4}$ & $\mathbf{5}$ & average \\
\hline education & 31.3 & 30.9 & 29.2 & 32.3 & 34.8 & $\mathbf{3 1 . 7}$ \\
health & 19.5 & 19.9 & 30.2 & 23.6 & 23.9 & $\mathbf{2 3 . 4}$ \\
employment \& income prog. & 18.9 & 22.2 & 18.6 & 18.7 & 19.8 & $\mathbf{1 9 . 7}$ \\
nutrition programs & 8.8 & 4.4 & 5.6 & 5.6 & 1.2 & $\mathbf{5 . 1}$ \\
social housing & 10.4 & 11.7 & 8.4 & 5.9 & 5.5 & $\mathbf{4 . 8}$ \\
police & 3.2 & 3.1 & 2.6 & 7.2 & 7.8 & $\mathbf{4 . 5}$ \\
water & 2.1 & 1.5 & 1.5 & 1.9 & 1.4 & $\mathbf{1 . 7}$ \\
electric lighting & 1.8 & 1.8 & 0.8 & 0.5 & 1.5 & $\mathbf{1 . 3}$ \\
communal households (ICBF) & 1.0 & 2.6 & 0.6 & 1.5 & 0.6 & $\mathbf{1 . 2}$ \\
public transport and roads & 1.4 & 0.8 & 0.9 & 0.8 & 2.0 & $\mathbf{1 . 2}$ \\
sports arenas & 1.3 & 0.9 & 1.3 & 0.7 & 0.8 & $\mathbf{1 . 0}$ \\
sewerage & 0.5 & 0.1 & 0.2 & 0.8 & 0.2 & $\mathbf{0 . 4}$ \\
garbage collection & 0.0 & 0.0 & 0.1 & 0.7 & 0.5 & $\mathbf{0 . 3}$
\end{tabular}

Source: Own calculations based on EPSOC (1999)

Table 8: Municipal Programs: Priorities for Cut-Back of Programs, by income quintile, Cali, September 1999 (percent)

\begin{tabular}{lrrrrrr} 
& $\mathbf{1}$ & $\mathbf{2}$ & $\mathbf{3}$ & $\mathbf{4}$ & $\mathbf{5}$ & average \\
\hline health & 0.9 & 0.2 & 0.4 & 0.8 & 0.5 & 0.6 \\
education & 0.8 & 0.6 & 1.1 & 0.7 & 1.1 & 0.9 \\
water & 2.8 & 1.0 & 1.1 & 0.7 & 0.3 & 1.2 \\
nutrition programs & 0.9 & 2.5 & 0.8 & 3.3 & 1.8 & 1.9 \\
employment \& income programs & 0.5 & 1.7 & 3.1 & 1.9 & 3.6 & 2.2 \\
garbage collection & 0.7 & 3.8 & 1.9 & 1.6 & 2.6 & 2.2 \\
sewerage & 1.1 & 3.3 & 4.2 & 3.2 & 2.1 & 2.8 \\
social housing & 3.3 & 1.1 & 5.5 & 5.5 & 3.7 & 3.8 \\
communal households (ICBF) & 10.5 & 9.5 & 5.5 & 5.9 & 8.0 & 7.9 \\
electric lighting & 7.6 & 14.1 & 12.5 & 10.1 & 9.4 & 10.8 \\
public transport & 18.2 & 12.9 & 12.9 & 17.5 & 18.0 & 15.9 \\
police & 18.6 & 17.2 & 16.6 & 15.1 & 12.9 & 16.1 \\
sports arenas & 33.9 & 32.1 & 34.3 & 33.6 & 35.9 & 33.9 \\
-------------------------
\end{tabular}

Source: Own calculations based on EPSOC (1999)

Additionally, the questions on evaluating education quality were only posed to those attending schools. As we had shown before, a large number of secondary school age children do currently not attend school. For such families, increasing education supply is obviously a high priority. 


\section{Conclusion}

This paper reported on how a rapid household survey was employed to inform municipal social policy in Cali, Colombia. While drawing on similar surveys in other cities and countries, the questionnaire was developed together with the local administration, academia and several civil society organizations. The survey needed to collect quantitative data on access and welfare as well as qualitative data on satisfaction levels and budget priorities within the city. Implementation time of the survey was short and costs were modest.

In the Cali context, a number of important new characteristics of poverty emerged from the city survey. For example, unemployment rates were found highest for the young with a completed secondary school degree, pointing to an important mismatch between the quality of education and the demands of the local labor market. Food insecurity surfaced as a serious concern for the poor with almost a third of the poorest population quintile experiencing hunger while the coverage of nutrition programs was found to have been minimal. And the survey was also the basis for the construction of a city poverty map, which showed that pockets of extreme poverty existed in comunas that were overall quite well off.

For the formulation of municipal social policy, the analysis of the survey proved especially insightful with respect to the distribution of city expenditures, service evaluation and population priorities. We found that, from a geographical perspective, all different types of city expenditures were distributed in an anti-poor way, favoring those areas in the city already quite well off. Satisfaction with city services varied considerably across different service types (with environmental cleanliness judged the worst) but relatively little across income groups. This result was also mirrored in budget priorities where a clear ranking of population preferences emerged, independent of the poverty status of the respondents. And the ranking cast considerable doubt on the metro project favored by the city administration at the time the survey was fielded.

Rapid city surveys can be an important tool for local social policy formulation. Apart from examining the specific local characteristics of poverty and social exclusion, population preferences and the distribution of city expenditures, such surveys can also be used, if applied regularly, to monitor social developments in the city over time. 


\section{References}

Alam, M., J. Sathaye, and D. Barnes. (1998), "Urban Household Energy Use in India: Efficiency and Policy Implications." Energy Policy, 26(11): 885-91.

Becerra, J. (1997), Patrones de Salud y Pobreza en Areas Urbanas de Bajos Ingresos y Respuesta de los Servicios de Salud a la Luz de la Equidad, Santiago de Cali.

Benjamin, S., N.W. Marler, G.J. de Kruijff. (1987), "Stretching the people's housing resources (Indonesia)." Habitat International, 11(2): 147-159.

Beukes, E. and A. van der Colff. (1997), "Aspects of the Quality of Life in Black Townships in a South African City: Implications for Human Development." Social Indicators Research, 41(1-3): 229-50

Booth, D., J. Hentschel, J. Holland, P. Lanjouw and A. Herbert (1998), Participation and Combined Methods in African Poverty Assessment: Renewing the Agenda (1998), DFID, London.

Borrell C., I. Rohlfs, M. Nebot, F. Dominguez-Berjon, M.I. Pasarin M.I., and J. Ferrando (2000), "Social Inequalities in Health Related Behaviors in Barcelona." Journal of Epidemiology and Community Health, 54(1): 24-30.

Gough, K.V. (1998), "House for Sale? The Self-help Housing Market in Pereira, Colombia". Housing Studies, 13(2): 149-60.

Grosh, M. and P. Glewwe (1999), Designing Household Survey Questionnaires for Developing Countries: Lessons from 15 Years of the Living Standards Measurement Study, World Bank, Washington D.C.

Gupta, H.S. and A. Baghel (1999), "Infant Mortality in the Indian Slums: Case Studies of Calcutta Metropolis and Raipur City." International Journal of Population Geography, 5(5): 353-366.

Hentschel, J. (1999), Contextuality and Data Collection Methods: A Framework and Application to Health Service Utilization, Journal of Development Studies 35(4): 64-94.

Jacobi, P.R. (1994), "Households and environment in the city of Sao Paulo; problems, perceptions and solutions". Environment and Urbanization, 6(2): 87-110.

Kaitilla, S. and W. Sarpong-Oti. (1993), "Employer-provided Housing in Papua New Guinea: Its Impact on House Ownership in the City of Lae." Habitat International, 17(4): 59-74.

Lanjouw, P. and M. Ravallion (1995), Poverty and Household Size, Economic Journal 105.

Martin, G. (2000), Violence in Cali, Background Paper for the City Development Strategy, mimeo, World Bank.

Mensah, J. and H.A. Whitney (1991), "Some Third World environmental perceptions and behaviours concerning urban waste: a survey of Techiman, Ghana." Canadian Geographer, 35(2): 156-165. 
Nord, M., A. Kumar, N. Raj, P. Webb and R. Hauser (2002), Comparing Household SurveyBased Measures of Food Insecurity Across Countries: Case Studies in India, Uganda, and Bangladesh, Paper Presented at the International Scientific Symposium on Measurement and Assessment of Food Deprivation and Under-Nutrition Sponsored by the Food and Agriculture Organization, Rome, Italy, June.

Paul, S. (1998), "Making Voice Work: The Report Card on Bangalore's Public Service." Washington D.C., World Bank, Development Research Group, Policy Research Working Paper 1921.

Protassenko, T. (1997), "Dynamics of Standard of Living in St. Petersburg during Five Years of Economic Reform." International Journal of Urban and Regional Research, 21(3): 445-53.

Rosenbaum, E. (1992), "Race and Ethnicity in Housing: Turnover in New York City, 1978-87." Demography, 29(3): 467-86.

Santamaria, M, (1999), Poverty in Cali - Basic Comparisons and Developments, Background Paper for the City Development Strategy, World Bank, mimeo, Washington.

Solans, Pilar (2000), Financial Situation in Cali, in: Cali City Development Strategy, mimeo, World Bank.

Swait, J. and G. Eskeland (1995), "Travel Mode Substitution in Sao Paulo: Estimates and Implications for Pollution Control." World Bank Policy Research Working Paper 1437: Washington, DC.

Urrea, F. and C. Ortiz (1999), Patrones Sociodemograficos, Pobreza y Mercado Laboral en Cali, Universidad del Valle.

Wei, B. (1998), "Ping'an Avenue: Conflict of Old versus New." Beijing Review, 40(41): 16-19.

World Bank (1997), The State in a Changing World, World Development Report 1997, Washington D.C.

World Bank (2002), Cali, Colombia - Towards a City Development Strategy, World Bank Country Study, Washington D.C. 